\title{
PERCEPÇÃO AMBIENTAL DE UNIDADES DE CONSERVAÇÃO: ESTUDO SOBRE AS LAGOAS DAS BATEIAS E DO JUREMA EM VITÓRIA DA CONQUISTA (BA)
}

\section{Environmental perceptions of conservation units: a study on the Bateias and Jurema lagoons in Vitória da Conquista (BA)}

\section{Percepción ambiental de unidades de conservación: estudio sobre las lagunas de las Bateas y del Jurema en Vitória da Conquista (BA)}

\author{
Daniel Cardoso Alves ${ }^{1}$ \\ Andrecksa Viana Oliveira Sampaio ${ }^{2}$ \\ Vilomar Sandes Sampaio ${ }^{3}$
}

\footnotetext{
1 Mestre em Ciências Ambientais; Professor da Faculdade de Educação da Universidade do Estado de Minas Gerais (UEMG), email dcauesb@gmail.com

2 Doutora em Geografia; Professora do Departamento de Gografia da Universidade Estadual do Sudoete da Bahia - UESB, email viladea@yahoo.com.br

3 Doutor em Geografia; Professor do Departamento de Gografia da Universidade Estadual do Sudoete da Bahia - UESB, email viladea@yahoo.com.br
}

\section{Resumo}

Este artigo é resultado da pesquisa que investigou a percepção ambiental dos moradores do entorno dos Parques Municipais Urbanos das Lagoas das Bateias e do Jurema (Vitória da Conquista, BA). Com base numa metodologia empírico-bibliográfica, constituída de três fases: revisão bibliográfica, pesquisa de campo (incluindo focus group) e análise de dados, discutiu-se sobre a importância da conservação ambiental a partir das percepções e representações sobre estas Unidades de Conservação (UC). O artigo, desta forma, contribui para o conhecimento de instrumentos como a influência da representação, a obrigatoriedade legal e o imperativo para a proteção dessas (UC). A análise fornece subsídios para a política ambiental da cidade, sobretudo no que se refere às subjetividades da (re)produção do espaço urbano.

Palavras-chave: Conservação ambiental; Unidades de Conservação Urbana; Percepção ambiental.

\begin{abstract}
This article is the result of the research that investigated the environmental perception of the residents of the Urban Municipal Parks of Lagoas das Bateias and Jurema (Vitória da Conquista, BA). Based on an empirical-bibliographic methodology, made up of three phases: bibliographical review, field research (including focus group) and data analysis, the importance of environmental conservation based on perceptions and representations about these Conservation Units (UC). The article thus contributes to the knowledge of instruments such as the influence of representation, the legal obligation and the imperative to protect these (UC). The analysis provides subsidies for the city's environmental policy, especially with regard to the subjectivities of (re) production of the urban space.
\end{abstract}

Keywords: Environmental Conservation; Units of Urban Conservation; Environmental perception

\section{Resumen}


Este artículo analiza los resultados de la investigación que investigó la percepción ambiental de los habitantes del entorno de los Parques Municipales Urbanos de la Lagoa das Bateias y de la Laguna del Jurema (Vitória da Conquista, BA). Con base en una metodología empírico-bibliográfica, constituida de tres fases: revisión bibliográfica, investigación de campo (incluyendo focus group) y análisis de datos, se objetivó discutir la importancia de la conservación ambiental a partir de las percepciones y representaciones sobre estas Unidades de Conservación. El artículo, de esta forma, contribuye al conocimiento acerca de la influencia de la representación, de la obligatoriedad legal y del imperativo de la protección de esas áreas ambientales. El análisis evidencia la necesidad de fortalecer su protección y revitalización, proporcionando subsidios para la política ambiental de la ciudad, sobre todo en lo que se refiere a las subjetividades de la (re) producción del espacio urbano

Palabras clave: Ambiental Conservación; Unidades de urbanización; Medio ambiente.

\section{Introdução}

Com a hegemonia do modelo de desenvolvimento capitalista industrial predominante entre as sociedades ocidentais, acentuou-se o uso predatório dos recursos naturais e tal processo produtivo influenciou as sociedades, tanto política quanto culturalmente, ao disseminar a ideologia do consumismo, da individualidade, da competitividade, agravando os problemas ambientais, decorrentes das explorações intensas da natureza. Frente a tal situação, faz-se necessário repensar as formas de proteção do meio ambiente, abordando as mais diversas estratégias políticoadministrativas, com especial atenção para o estudo das subjetividades humanas. Nessa perspectiva, os estudos voltados para a compreensão das inter-relações entre o homem e o ambiente, com vistas à proteção e ao cuidado deste, têm se ampliado e se apoiado em mecanismos identificadores das necessidades, das aspirações, dos anseios, das opiniões, das atitudes e dos valores conferidos pelas pessoas ao espaço em que habitam.

A identificação e a valorização das percepções humanas podem ser pensadas a partir de estudos de Percepção Ambiental, que consideram os aspectos subjetivos que mobilizam as atitudes das pessoas em relação ao meio em que vive e apontam caminhos para a proteção holística do meio ambiente. Segundo Fernandes et al (2003), os estudos de Percepção Ambiental referem-se ao ato do sujeito perceber o ambiente em que está inserido e despertar-se para a sua consecutiva proteção. Tais análises tiveram importância evidenciada pela Organização das Nações Unidas para a Educação, a Ciência e a Cultura (UNESCO), no ano de 1973, especificamente no que tangia à capacidade de possibilitarem uma análise totalizante das formas sustentáveis de apropriação do meio ambiente. 
No Brasil, a inserção de estudos de Percepção Ambiental em instituições acadêmicas ou engajadas com a formulação de políticas públicas, que tratam das questões ambientais, tem conduzido a reflexões que ultrapassam as discussões lineares sobre sustentabilidade e avançam sobre o campo da responsabilidade socioambiental frente à identificação, sistematização, análise, interpretação e valorização dos dados que são humanamente perceptivos. No entanto, para que se consiga alcançar um patamar satisfatório de responsabilidade e de vinculação ética das pessoas com o meio ambiente é preciso que, nas cidades brasileiras, os gestores públicos reconheçam o planejamento, a participação popular e a gestão administrativa como inseparáveis no desenvolvimento das políticas públicas ambientais e que, apenas conjuntamente podem fornecer propostas e soluções para as questões dessa natureza.

Neste contexto, este artigo apresenta resultados do estudo de percepção ambiental sobre duas Unidades de Conservação no perímetro urbano de Vitória da Conquista (BA), o Parque Municipal Urbano da Lagoa do Jurema e o Parque Municipal Urbano da Lagoa das Bateias. Buscando compreender as formas de apropriação sociocultural destes locais frente às atuações da sociedade civil e do poder público. A pesquisa teve como objetivo analisar a concepção de sustentabilidade que fundamentou a institucionalização destas Unidades de Conservação, apreender e comparar percepções ambientais dos moradores do entorno das duas áreas pesquisadas. Para tanto, definiu um enfoque metodológico sincrônico-diacrônico, compreendendo tanto a realidade contemporânea quanto o período da institucionalização destas Unidades de Conservação, ocorrida em 2007.

A partir da institucionalização do Sistema de Unidades de Conservação (SNUC) (Lei $N^{\circ}$ 9.985), em 2000, foram estabelecidos os critérios para a criação, a implantação e a gestão das Unidades de Conservação no Brasil, definidas como "espaço territorial e seus recursos ambientais, incluindo as águas jurisdicionais, com características naturais relevantes, legalmente instituído pelo Poder Público, com objetivos de conservação e limites definidos" (BRASIL, 2000, art. $2^{\circ}$ ), com regime especial de administração, para garantir adequada proteção. As Unidades de Conservação aqui estudadas, os Parques Municipais Urbanos da Lagoa das Bateias e da Lagoa do Jurema, inserem-se no grupo das Unidades de Uso Sustentável, definidas pelo Código Municipal do Meio Ambiente de Vitória da Conquista (Lei N $\left.{ }^{\circ} 1.410 / 2007\right)$ como áreas de proteção ambiental, o que significa que nestes locais somente poderiam ser desenvolvidas atividades científicas, de educação, de interpretação ambiental, de recreação em contato com a natureza ou de 
turismo ecológico, e isto desde que respeitados os demais critérios e restrições estabelecidos pela legislação do SNUC.

No entanto, passados alguns anos da criação das UC, verifica-se que à criação legal não correspondeu uma proteção efetiva, pelo contrário, não há nem o conhecimento da sociedade sobre as UC, inseridas em áreas altamente urbanizadas, sem haver sequer demarcação de área em uma delas, a da Lagoa do Jurema.

Há, assim, questionamentos a serem feitos sobre a pertinência dos instrumentos legais, se aplicados sem as correspondentes ações públicas de proteção e preservação, além de uma evidente necessidade de discussão sobre estes Parques, sobretudo no que se refere aos mecanismos socioculturais envolvidos na conscientização da população da cidade a respeito deles, com muitas pessoas inclusive desconhecendo suas existências. Neste sentido, ao propor a discussão sobre a importância da conservação ambiental e a percepção ambiental de tais lugares, problematizou-se também os processos de implantação dos mesmos na categoria de Unidade de Conservação, bem como os processos envolvidos.

De início, ressalta-se que o desenvolvimento urbano desta cidade, semelhante ao que aconteceu em grande parte dos municípios brasileiros, foi acompanhado de uma relação caótica com o meio ambiente. Uma evidência deste caos em Vitória da Conquista é a canalização subterrânea do rio que passa pelo centro da cidade, o Rio Verruga, praticamente desconhecido pela comunidade, com suas nascentes localizadas no perímetro urbano, e que é confundido com esgoto ao vir à tona, mais adiante, em seu leito de drenagem natural. Para Oliveira et al (2003), esta situação revela o caráter violento da ocupação do território local: "o rio foi engolido pela cidade e hoje a atravessa subterraneamente, confundido com esgoto, ignorado por seus habitantes. A cidade se sobrepõe ao rio e ele permanece quieto, silencioso, rio sem barulho de água que corre, rio que não se vê" (OLIVEIRA et al, 2003, p.19).

Assim como a sociedade local desconhece a existência do rio, também desconhece a criação destes parques municipais urbanos, criados para preservar as áreas das lagoas das Bateias e do Jurema, tão desvalorizadas pela população local quanto o rio Verruga.

Talvez justamente como decorrência destes processos históricos caóticos de ocupação territorial desvinculada de preocupações ambientais, atualmente, o município enfrenta a falta de água como um dos principais problemas socioambientais, com longos períodos de seca e escassez deste bem natural, em consonância com o maior problema 
ambiental do mundo. Ao mesmo tempo, as iniciativas voltadas para as questões ambientais assumem vieses contraditórios, sobretudo no que se referem às políticas de proteção ambiental de Unidades de Conservação, como as que envolvem a proteção à Lagoa das Bateias e à Lagoa do Jurema, origem e sentido primeiro deste parques municipais.

Para este estudo, definiu-se uma pesquisa “não-probabilística” (GIL, 2011), visando à articulação dos conceitos de percepção ambiental à proposição de possibilidades para a proteção ambiental a partir das reflexões sobre os pensamentos e as percepções das comunidades habitantes do entorno dos mesmos. Com isto, foi possível alcançar uma apreensão holística das significâncias e práticas das comunidades em relação aos Parques das Bateias e do Jurema de forma contextualizada, possibilitando a compreensão e a interpretação da realidade local a partir de conteúdos humanos nem sempre explícitos. As etapas da pesquisa envolveram pesquisa bibliográfica, pesquisa documental sobre a criação dos parques e pesquisa de campo, com realização de entrevista individual e entrevistas focus group (GIL, 2011) com moradores do entorno dos parques.

A análise dos resultados foi feita a partir da constituição de unidades de sentido, adequadas para fins de redução, exibição, conclusão e interpretação das mesmas. Algumas questões nortearam a pesquisa: que pressupostos fundamentaram a constituição destas áreas como Unidades de Conservação? Qual o grau de participação social para a criação destas UC? Que noção de sustentabilidade prevalece entre os sujeitos sociais moradores do entorno? É pertinente a concepção destes locais como unidades de conservação? O artigo discute, portanto, aspectos dos estudos de Percepção ambiental, considerando a capacidade perceptiva das pessoas como dimensão simbólica, reveladora de significados, valores, crenças, mitos e utopias materializados na forma de paisagens, referenciando-se em temas como responsabilidade e conscientização socioambiental. Apresenta resultados da pesquisa de campo, discutindo as características locais, a atuação do poder público e da sociedade civil, efeitos da apropriação social sobre os lugares e a percepção ambiental das comunidades sobre o processo de constituição das UC.

\section{Percepção ambiental: um poder simbólico para a atitude social}


Os estudos de percepção ambiental indicam a existência de múltiplas interpretações para uma dada paisagem humanamente percebida. Essa percepção, carregada de conteúdos racionalizados, mas também relativos à representação e ao universo simbólico-cultural constitui uma base para a consciência humana sobre a vida, o meio ambiente e o mundo.

Assim, tais estudos contribuem para a tomada de consciência da realidade de forma mais ampla e holística. Todavia, o estudo sobre a percepção ambiental requer também um olhar cauteloso, pois, conforme Santos (1988), se, à primeira vista, for observada simplesmente a estrutura e materializada morfologicamente sob a forma de paisagem, a compreensão torna-se enganadora, não sendo capaz de fornecer ao observador uma compreensão total da realidade que salta aos olhos, mas que muitas vezes não evidencia dimensões não aparentes que são, contudo, básicas e responsáveis por sua gênese, como as dimensões histórica, social, econômica, política e cultural.

Como afirmam Corrêa e Rosendahl (2004) a paisagem tanto tem dimensão morfológica (sendo um conjunto de formas criadas pela natureza e pela ação humana) e funcional (apresentando relações entre suas partes) quanto também apresenta uma dimensão histórica, visto que "a paisagem é portadora de significados, expressando valores, crenças, mitos e utopias: tem assim uma dimensão simbólica" (CORRÊA; ROSENDAHL, 2004, p. 8).

Portanto, a fim de não resumir a percepção ambiental somente àquilo que se vê, ou simplesmente à paisagem natural, entende-se que a explicação de uma dada realidade pelo viés da sua paisagem não termina na percepção morfológica, muito pelo contrário, as formas são apenas os indícios concretos do conteúdo que ela carrega, pois:

A cada instante, há mais do que o olho pode ver, mais do que o ouvido pode perceber, um cenário ou uma paisagem esperado para serem explorados. Nada é vivenciado em si mesmo, mas sempre em relação aos seus arredores, às seqüências de elementos que ele conduzem, à lembrança de experiências passadas, "[...] Cada cidadão tem vastas associações com alguma parte de sua cidade, e a imagem de cada um está impregnada de lembranças e significados" (LYNCH, 1997, p. 1).

Nesse sentido, pode-se dizer que toda paisagem, como forma concreta e perceptível de uma parte da realidade, é reveladora do contexto sociocultural, político, histórico e econômico, sendo fruto da dinâmica de uma sociedade, que atuou num dado momento histórico sobre o ambiente, sob a égide das diversas culturas predominantes na época. 
É nessa perspectiva e, principalmente, entendendo a paisagem ambiental como o processo de transformação humana do espaço natural, do qual participam os diversos atores sociais, que o estudo de percepção ambiental possibilita uma análise coerente dos impulsos humanos que a promovem, em que "todas as paisagens possuem significados simbólicos porque são o produto da apropriação e transformação do meio ambiente pelo homem" (CORRÊA; ROSENDAHL 2004, p. 108).

Busca-se, assim, uma apreensão dos anseios do homem sobre o espaço que, na forma de paisagens, expõe morfologicamente os valores culturais de uma sociedade. No entanto, esses valores - que não representam uma vontade universal das sociedades, pois refletem "a imagem de uma determinada realidade [que] pode variar significativamente entre observadores diferentes." (LYNCH, 1997, p. 7) - acabam sendo massificados diante da predominância dos modelos culturalmente hegemônicos, em que:

Um grupo dominante procurará impor sua própria experiência de mundo, suas próprias suposições tomadas como verdadeiras, como a objetiva e válida cultura para todas as pessoas. O poder é expresso e mantido na reprodução da cultura. Isto é melhor concretizado quando é menos visível, quando as suposições culturais do grupo dominante aparecem simplesmente como senso comum (CORRÊA e ROSENDAHL, 2004, p. 104-105).

A percepção ambiental, dirigindo olhares mais holísticos à paisagem geográfica, não se limita, assim, ao aparente, nem tampouco a um olhar ingênuo, mas estabelece relações sistêmicas e permite perceber as contradições que não são visíveis no plano aparente. Neste sentido, recomenda-se cuidado, pois, se o olhar dirigido à paisagem for tomado de maneira isolada, tal análise não permitirá o entendimento do real em sua total complexidade.

Parafraseando Morin (2004), não se trata de simplesmente inscrever as coisas ou os acontecimentos em um determinado quadro ou perspectiva, mas, antes, de procurar compreender as "relações e inter-retro-ações entre cada fenômeno e seu contexto, as relações de reciprocidade todo/partes: como uma modificação local repercute sobre o todo e como uma modificação do todo repercute sobre as partes” (MORIN, 2004, p. 25).

Assim, compreender a essência sociocultural de uma paisagem não é nada simples, pois exige do sujeito a capacidade do reconhecer-se, saber dos seus valores, dos seus mitos, e dos fatores que determinam a sua dinâmica social. Preso a sua condição intrínseca de ser social e ser simbólico, o sujeito não está numa posição de mero espectador de paisagens, nem de simples observador de aparências, não estando 
alheio à realidade social do seu lugar, pois a paisagem "refere-se ao resultado do elo afetivo do homem com o espaço fruto de uma relação temporal" (TUAN, 1980). Caso deseje assumir a posição de mero espectador, perceberá a paisagem apenas "pela aparência, por algum critério formal de beleza" (TUAN, 1980, p. 74), negligenciando a capacidade de estabelecer as conexões complexas entre as partes que integram aquilo que se vê, uma vez que:

Não somos meros observadores desse espetáculo, mas parte dele; compartilhamos o mesmo palco com os outros participantes. $\mathrm{Na}$ maioria das vezes, nossa percepção da cidade não é abrangente, mas antes parcial, fragmentária, misturada com considerações de outra natureza. Quase todos os sentidos estão em operação, e a imagem é uma combinação de todos eles (LYNCH, 1997, p. 2).

O reconhecimento precisa abarcar outras dimensões, para não se limitar às aparências ou considerar apenas o que a superficialidade alcança. É preciso assumir uma posição de questionador da realidade que, direta ou indiretamente, individual ou coletivamente, os sujeitos produziram e que se materializou sob a forma de paisagem.

Considera-se que a apropriação e a produção sociocultural do meio ambiente, pelos mais diferentes tipos de sociedades, têm como resultado as múltiplas paisagens ambientais que, ao contrário do que alguns pensam, não são formas estáticas da realidade, mas representações momentâneas da dinâmica social que, em sua totalidade espaço-temporal, são reveladoras de histórias e símbolos, o que permite dizer, conforme Corrêa (2005, p. 158), que “[...] a própria cidade é uma grafia [...]”, já que resultam da materialização de mitos, utopias, crenças e valores impressos espacialmente pelas sociedades em seus mais diferentes tempos históricos.

A percepção ambiental manifesta o viver social, considerando que, longe de ser somente beleza e um conjunto de objetos, a paisagem é reveladora das mazelas sociais, em que as tentativas de camuflagem da problemática social são, nitidamente, contrastadas com a miserabilidade da grande maioria da população que não desfruta dos mesmos direitos de uso do meio ambiente e dos recursos nele disponíveis. Compreender a subjetividade que toda paisagem carrega através dos estudos de percepção ambiental, é, então, repensar-se como sujeito e perceber nas formas concretas, que saltam aos olhos, os ideais, as práticas, as culturas e os valores de uma sociedade, enfim, é reconhecer-se para entender o meio ambiente como um produto sociocultural singular dentro de diversas pluralidades. 


\section{Implicações socioambientais do modelo de configuração urbano-espacial}

O espaço urbano, de acordo com Carlos (1994, p.23), é a materialização da dinâmica social, logo, produto, condição e meio para a reprodução da sociedade. Para o autor, como resultado do processo de produção capitalista, o espaço revela contradições sociais em suas paisagens, materializando-se desigualmente, expressando as diferenças sociais, a justaposição de riqueza e pobreza, estando a segregação estampada na paisagem, que revela a exploração do trabalho pelo capital fundado na propriedade.

Ainda segundo Carlos (1994), entender a dinâmica da urbanização nas cidades brasileiras, a (re)produção do espaço urbano, requer olhar para a trajetória da sociedade de classes, pois o seu movimento, em favor da mobilidade do capital, é revelador das históricas violências urbanas (exclusões política, econômica, social, cultural e espacial) às quais os habitantes citadinos estão submetidos, cuja expressão máxima se dá na apropriação desigual dos espaços, dos recursos e na marginalização social.

Nesse sentido, o acelerado processo de urbanização no Brasil, associado ao rápido fenômeno da industrialização, possibilitou acelerar as formas predatórias de exploração da natureza e teve repercussão na questão ambiental, uma vez que todo processo de urbanização implica, necessariamente, em impactos na harmonia natural de determinado lugar.

No Brasil, o processo de urbanização foi marcado por tentativas de adoção de modelos de urbanização copiados de outros países, sem que houvesse uma reflexão sobre a pertinência local, sequer planejamento urbano adequado. Para Santos (1982), enquanto nos países industrializados a incorporação gradativa de novas tecnologias trouxe vantagens às cidades, "nos países subdesenvolvidos registrou-se uma intrusão brutal das técnicas evoluídas, seletivas no início e depois mais sistemáticas" (SANTOS, 1982, p.95).

O processo de urbanização brasileira, assim, tanto acentuou a problemática urbana decorrente de falta de infraestrutura adequada às cidades, como agravou a questão socioambiental no país, no que se refere, sobretudo, às más condições de vida, ao desemprego, à explosão demográfica, à violência, à desigualdade, às sub-moradias e outros fatores que contribuem para o crescimento desordenado e segregado das cidades, levando autores, como Gomes (2002, p. 172), a denominarem-nas de "cidades partidas". E ainda: 
O processo de urbanização no Brasil tem suas especificidades marcadas pelas determinações impostas pelo modelo econômico excludente e segregador implantado no país, decorrente da lógica capitalista de produção. $\mathrm{O}$ acentuado crescimento urbano, ocorrido no período entre 1930 e 1980, realizou-se a par do crescimento econômico e de um processo de concentração de riquezas que excluiu a grande maioria da população brasileira (GOMES, 2002, p. 171).

A discussão da questão ambiental brasileira perpassa, portanto, pelo entendimento do processo de apropriação do seu território, que se deu de modo bastante predatório e foi agravado por um Estado de atuação mínima, cujas políticas públicas desvinculam os problemas ambientais das demais dimensões sociais, dificultando, quando não excluindo, a efetiva participação da sociedade dos direcionamentos da plena apropriação espacial e dos recursos disponíveis.

Como consequência desse modelo de urbanização, as cidades brasileiras convivem com problemas diversos e crescentes que, se analisados de forma sistêmica, terão ligação direta com os problemas estruturais originários do inadequado processo de configuração urbano-espacial, agravado pela política de mercantilização da ocupação, de benfeitorias dos espaços urbanos e de apropriação dos recursos naturais. Segundo Ferraz:

A cidade de Vitória da Conquista não foge à regra do inadequado processo de urbanização adotado pelo Brasil. Para Ferraz (2001), a dinâmica urbana local é repleta de contradições e conflitos e "sua configuração territorial é resultado da ação de vários sujeitos produtores do espaço urbano, em constante luta pela conquista de seus interesses e necessidades" (FERRAZ, 2001, p. 21).

Situada numa área de entroncamento rodoviário (BR 116, BR 415 e BA 262, além de outras estradas vicinais) e situada a $522 \mathrm{~km}$ da Capital da Bahia, o município é o terceiro do Estado, com população de 306.866 habitantes (IBGE 2010), sendo 89\% residentes em zona urbana, concentrando suas atividades no setor terciário. Com clima semiárido a sub-úmido, o município registra temperatura média anual de $20,2^{\circ} \mathrm{C}$ e baixos índices pluviométricos, com duas ecorregiões vegetais: a formação florestal decidual montana e a caatinga. A rede hidrográfica do município conta com alguns rios e riachos, sobretudo na zona rural, sendo que o único corrente na zona urbana a atravessa subterrâneo e inutilizado. A cidade possui três Unidades de Conservação instituídas: o Parque Municipal da Serra do Periperi, o Parque Municipal Urbano da Lagoa das Bateias e o Parque Municipal Urbano da Lagoa do Jurema, sendo os dois últimos os objetos deste estudo. 


\title{
As Lagoas, os Parques Municipais Urbanos e as pessoas do lugar
}

O ambiente lacustre da Lagoa das Bateias foi transformado em Unidade de Conservação em 2007 (Lei n 1.410), com o nome de Parque Municipal Urbano, mas, desde antes, já em 1996, a Lagoa das Bateias havia sido decretada como área de preservação, sem qualquer tipo de ação efetiva de proteção ou revitalização. A área está situada na zona urbana e circundada por bairros populosos. A Lagoa tem potencial hídrico relevante e integra a sub-bacia do Riacho Santa Rita, integrante da bacia do Rio Verruga, que, por sua vez, integra a grande bacia do Rio Pardo. Impactos ambientais negativos na Lagoa das Bateias repercutem, assim, no equilíbrio de todas as demais bacias que com ela se comunicam e vice e versa.

$\mathrm{Na}$ cidade, a área era considerada, historicamente, como espaço insalubre, uma área de charco, mas sua ocupação humana foi agravada nos anos 1990, fase de crescimento urbano acelerado, e, desde então, foi crescentemente impactada, em meio ao descompasso do poder público na criação e aplicação de instrumentos legais para a sua proteção, se constituindo como lugar de moradia para populações carentes. Almeida e Pedlowski afirma:

\begin{abstract}
As proximidades das lagoas são de modo geral áreas rejeitadas pelo mercado imobiliário privado, cujas marcas de exclusão social são evidenciadas pelas condições precárias de moradia, pelo baixo grau de escolaridade, baixa renda familiar, significativo índice de desemprego, ausência de serviços e/ou equipamentos públicos, como também pelos riscos que boa parte da população encontra-se diariamente exposta devido à proximidade de suas casas com as lagoas (ALMEIDA e PEDLOWSKI, 2007, p. 5).
\end{abstract}

Situada assim entre bairros populosos, desprovidos de infraestrutura básica, a Lagoa (figura 1) encontrou-se crescentemente em risco e vulnerabilidade, sobretudo dado o descarte dos resíduos domésticos em sua borda. Foi tombada pelo poder público municipal em 1996, na tentativa de regulação da área, alegando suas múltiplas importâncias: “[...] área de nascente, cinturão verde, captação de água pluvial, quebra vento em benefício dos bairros vizinhos, influência no microclima local e benefícios para a população residente" (PMVC, DECRETO Nº 8.594, 1996). 
Figura 1 - Foto aérea da Lagoa das Bateias, Vitória da Conquista - BA.

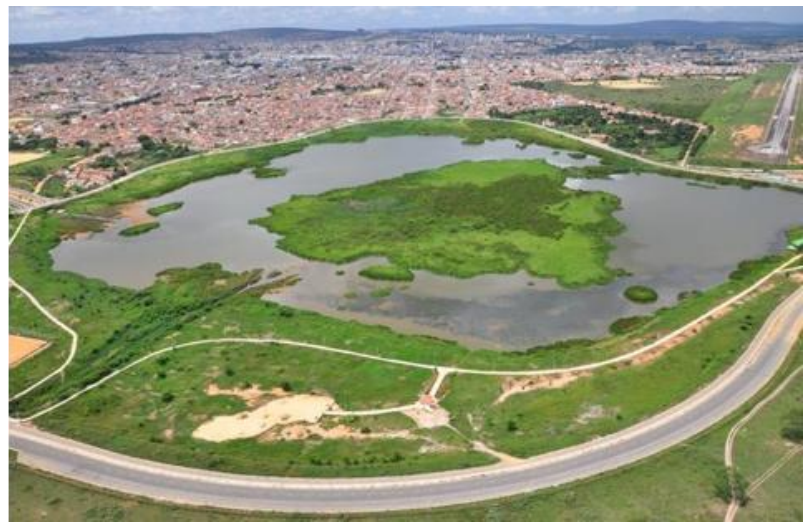

Fonte: Disponível em: http: //www.blogdofabiosena.com.br. Acesso em 12 mai. 2013.

Em 2005 iniciou-se a implantação do Parque das Bateias, com o remanejamento de moradores para áreas próximas, dividindo-se a população residente entre dois loteamentos, num processo de negociação que envolveu reuniões, assembleias e visitas domiciliares (ALMEIDA et al, 2008). Entre 2007 e 2008, período da institucionalização do Parque das Bateias, entrou em execução o Programa Federal de Urbanização, Regularização e Integração de Assentamentos Precários, que promoveu importantes melhorias na área da Lagoa, com implantação de vias de acesso, pavimentação asfáltica, iluminação pública, segurança e divulgação da área como espaço ambiental e de lazer. Tais melhorias contribuíram para minimizar o grau de insatisfação dos moradores desalojados pelas obras de urbanização por ocuparem áreas insalubres no entorno da Lagoa. Ressalte-se que a Secretaria Municipal do Meio Ambiente (SEMMA) passou a cuidar da área, a partir da sua transformação em Unidade de Conservação.

O outro local aqui pesquisado, a Lagoa do Jurema, é um ambiente lacustre historicamente caracterizado por uma situação de risco e vulnerabilidade e, assim como a Lagoa das Bateias, foi elevada à categoria de Unidade de Conservação em 2007, por força da Lei $\mathrm{n}^{\mathrm{o}}$ 1.410, que instituiu o Código Ambiental do Município de Vitória da Conquista, passando, desde então, a ter sua área denominada Parque Municipal Urbano da Lagoa do Jurema (PMULJ).

Situada no bairro Jurema, a lagoa de mesmo nome margeia a Avenida Integração, parte urbana da rodovia BR-116 (Rio-Bahia), que atravessa a cidade, dividindo-a em duas. Apesar da Lagoa do Jurema estar localizada nas cotas mais baixas da cidade, possuir nascente do Rio Verruga e ser receptora das águas de chuva de toda 
bacia oeste e sudoeste da cidade, somente foi tratada como matéria legal a partir da aprovação do Código Ambiental de 2007.

A lagoa não só foi omitida dos atos orgânicos do poder público municipal, como também nunca se configurou no imaginário social dos conquistenses como uma lagoa, quiçá um Parque Municipal e/ou uma Unidade de Conservação, dada a situação de eterna degradação socioambiental materializada em sua paisagem. Ao contrário, a área desta lagoa também vem sendo historicamente ocupada de forma irregular pela população, o que aumenta os riscos de vulnerabilidade socioambiental, e os moradores do entorno são desprovidos de estruturas básicas de saneamento, serviços urbanos e equipamentos comunitários essenciais, culminando na apropriação dissonante com os preceitos legais sobre áreas de Unidade de Conservação.

A ocupação da área da Lagoa do Jurema revela a exclusão da população de baixa renda que, numa constante luta contra as adversidades socioambientais pela sobrevivência, se instalou nesse ambiente insalubre com péssimas condições de infraestrutura e de moradia, cujas casas apresentam bases estruturais inseguras, com infiltrações e rachaduras aparentes, em que os riscos de desmoronamento são eminentes. Ao mesmo tempo em que a população sofre com as péssimas condições estruturais de suas moradias, enfrenta constantes ordens de desocupação da área por parte do poder público, com o argumento de que é uma área de proteção ambiental e que, portanto, não pode ser residencial de acordo com os preceitos do Código de Ambiental do Município. São constantes as demolições das construções impróprias e o remanejamento destes moradores.

A localização geográfica da Lagoa do Jurema (figuras 2 e 3) também se configura como um elemento influenciador para a degradação da área e dos recursos naturais, ampliando o risco de vulnerabilidade. A deterioração ambiental local é evidente e crescente. À institucionalização da lagoa como Unidade de Conservação não correspondeu nenhum ato de proteção ou de efetiva gestão, sendo constante a utilização da área para descarte de resíduos e detritos provenientes da construção civil e dos lixos domésticos, tendo a aparência de "lixão", o que contribui também para a proliferação de vetores de doenças. Assim, não se constata, até o momento, a efetiva atuação do poder público voltada para a proteção e/ou revitalização da área da Lagoa do Jurema, havendo apenas a colocação de uma cerca no perímetro, mas nenhuma ação que vise a recuperação da área degradada ou a efetiva transformação da mesma em um Parque. 
Figura 2 e 3 - Parque Municipal Urbano da Lagoa do Jurema, 2012.
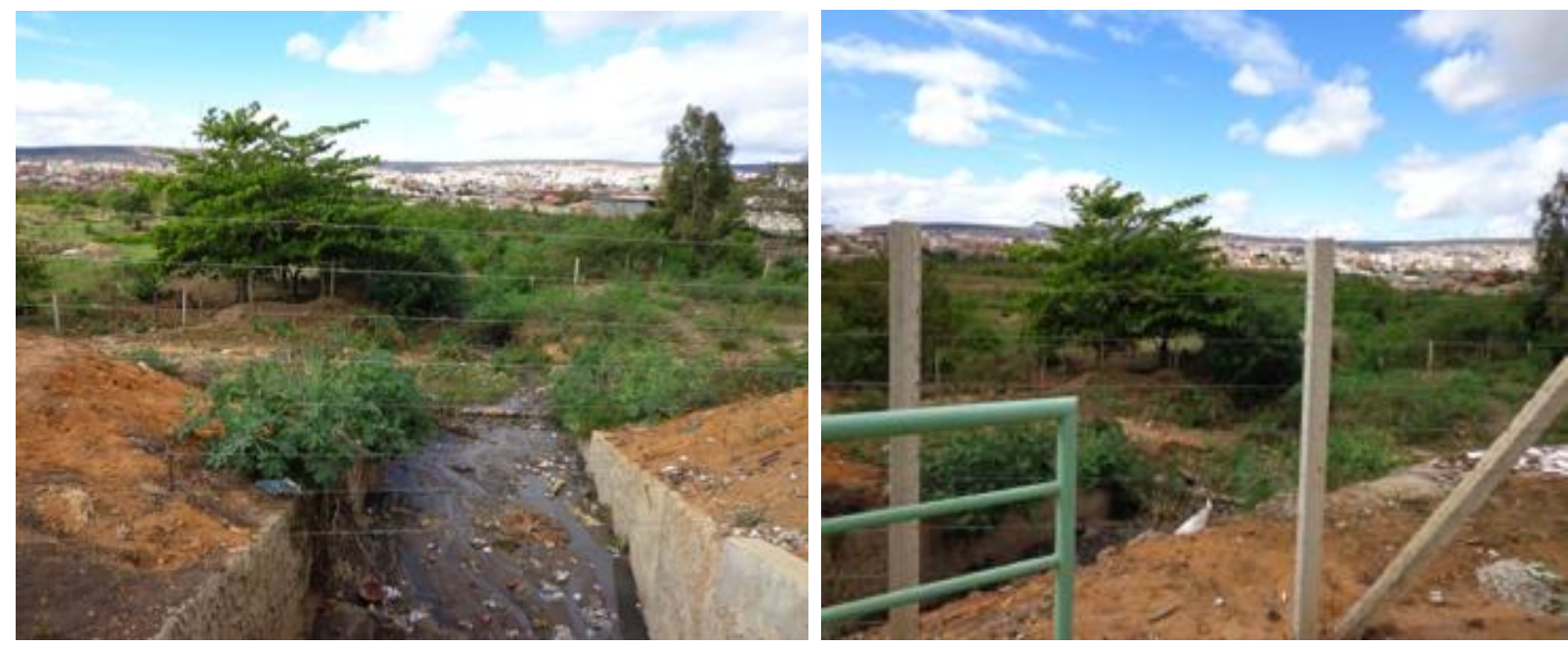

Fotografia: "Daniel Cardoso Alves", out/2012

A elevação da Lagoa do Jurema à categoria de Unidade de Conservação e a consequente transformação de sua área em Parque Municipal Urbano em 2007, em nada diminuiu os riscos de vulnerabilidade socioambiental presentes, o que reforça a ideia de que os citados aparatos legais não passaram de protocolos formais, dada a inaplicabilidade dos mesmos, ao tempo em que a constante degradação do Parque do Jurema aumenta os aspectos nocivos à vida da população aí residente. Tal situação tem levado alguns estudiosos e pesquisadores locais a questionar se, de fato, a área da Lagoa do Jurema pode ser considerada uma Unidade de Conservação ou um Parque Municipal.

\section{Representação e Percepção Ambiental dos moradores dos Parques}

A pesquisa de campo com os moradores, organizados em turmas diferentes considerando-se as respectivas localidades das Bateias e do Jurema, tomou por base a metodologia do focus group (GIL, 2011), adotando-se o modelo proposto por Lynch (1997), segundo o qual o imaginário social reflete a identidade, a estrutura e o significado conferidos pelo sujeito ao ambiente. Foram realizadas em 2013 e, na comunidade das Bateias foram entrevistados doze moradores, e igual número na comunidade do Jurema.

Dados levantados junto ao IBGE (2000) indicam que a população dos bairros próximos do Jurema é mais pobre, com um rendimento médio anual inferior ao dos moradores da área próxima a lagoa das Bateias. Também são altos os índices de analfabetismo (IBGE/2000) nos bairros das Bateias e do Jurema, correspondendo a 30\% 
e $18 \%$ (nos bairros centrais ou de classe média da cidade os índices estão entre $6 \%$ e 7\%). Tais percentuais dificultam o trabalho de conscientização socioambiental, requerendo métodos apropriados para que se possa desenvolver processos locais de educação ambiental.

Questionados sobre o conceito de Unidade de Conservação, a maioria dos entrevistados (67\%) da comunidade Bateias, apesar de saber da existência de UCs na cidade, não conseguiu conceituá-las como uma área natural protegida pelo poder público. Esses mesmos 67\% esqueceram-se que o próprio Parque das Bateias, área em que residem, também é uma Unidade de Conservação. Por outro lado, $17 \%$ não souberam opinar sobre o conceito de Unidade de Conservação, e outros $17 \%$ se referiram a Unidade de Conservação como órgão vinculado ao poder público, inclusive citando alguns. Já na região do Jurema, mais da metade dos moradores entrevistados (75\%) não tinha qualquer conhecimento sobre o fato de morar no entorno de uma Unidade de Conservação.

Pelas respostas percebe-se haver uma confusão entre o que é uma Unidade de Conservação e os órgãos públicos associados à esfera ambiental, sendo que um grande número citou outras praças públicas, a EMBASA e o IBAMA como exemplos de UC, demonstrando desinformação e equívoco no entendimento sobre o tema. Ressalta-se que mais da metade dos entrevistados, em ambos os grupos, afirmou não saber que mora no entorno de uma Unidade de Conservação, apesar de ambas estarem oficialmente instituída desde o ano de 2007. No mesmo sentido, também desconhecem o que é um Parque Municipal, não associando tal instância à proteção ambiental, atrelando-a mais à ideia de lazer. Desta forma, evidencia-se que não há qualquer sensibilização da população do entorno das Lagoas para as questões ambientais e não há nenhuma ação de educação ambiental.

Pelas respostas obtidas, percebe-se que os projetos de criação destas duas Unidades de Conservação aconteceram sem nenhum envolvimento da população que reside em suas imediações, o que não resultou sem o estabelecimento de vínculos de responsabilidade entre eles e os locais. Evidenciam-se práticas conflituantes, como acúmulo de lixo e invasão das áreas, com princípios de conservação e proteção, também por falta de políticas eficazes de conscientização da população local e de efetivas ações de proteção ambiental.

As Bateias e as taboas do Jurema, como popularmente são conhecidos os Parques das Bateias e do Jurema, são áreas resultantes de um processo de ocupação 
irregular, cujas investidas públicas no tocante à criação de leis ambientais e ações de proteção e revitalização de suas áreas são recentes. A apropriação social das áreas desses Parques decorreu da necessidade habitacional de pessoas que, sem atender às condições impostas pelo mercado imobiliário, se viram obrigadas a habitar áreas social e economicamente desvalorizadas. As ocupações ocorreram de forma gradativa, à revelia de qualquer controle por parte do poder público, que somente voltou a sua atenção para uma delas (a área do Parque das Bateias) a partir do ano de 1996, com a promulgação do Decreto Municipal No 8.594/96, que reconheceu a área da Lagoa das Bateias como ambientalmente importante para a cidade de Vitória da Conquista e, portanto, instituindo-a como área de preservação ambiental.

Com relação à área do Parque do Jurema, a atenção por parte do poder público, ainda que apenas normativa, somente se deu com a aprovação do Código Ambiental do Município, no ano de 2007. Quando se considerou os motivos que originaram as moradias em áreas das Lagoa das Bateias e do Jurema, 58\% dos entrevistados afirmaram que o principal motivo para a aquisição de terrenos no local foi a facilidade econômica, pois os lotes eram vendidos por valores baixos quando comparados aos de outros locais, mediante processos formalmente simplificados, viabilizando a compra por pessoas de baixa renda, com ocupações em atividades informais.

A primeira mudança de percepção ambiental oficial das áreas dos Parques das Bateias e do Jurema, ocorreu apenas nos anos de 1996 e 2007, respectivamente. Entretanto, para a população local, o processo de transformação das áreas é perceptível desde o momento de ocupação, ou seja, desde os primeiros aterros da área alagada. Assim, quando questionados sobre 'percepções de mudanças, ao longo do tempo, nas áreas que residem', os moradores mais antigos de ambos os parques são unânimes em relatar o processo de ocupação de uma área alagada, sem qualquer tipo de infraestrutura urbana. Aos poucos a lagoa foi sendo aterrada pelos próprios compradores dos lotes, configurando-se como uma área "pronta" para a construção das residências. Segundo os moradores mais antigos, em uma década de ocupação, toda a área da borda das lagoas estava completamente habitada, permanecendo isolados, e por pouco tempo, apenas aqueles lotes que não haviam sido inicialmente aterrados. Aos poucos, o poder público realizou algumas ações isoladas de legalização da energia elétrica e do abastecimento de água, durante muito tempo utilizadas de forma clandestina (os populares "gatos de luz e água"). 
Para $42 \%$ dos moradores da vizinhança do Jurema, as mudanças percebidas, ao longo do tempo, concentram-se no aumento do número de residências e moradores, mesmo com a política do poder público voltada para a retirada dos ocupantes de 'áreas inapropriadas'; já 33\% consideraram a derrubada de residências para a desocupação de áreas impróprias, enquanto $25 \%$ se referiram ao aumento da concentração dos "lixões" no local.

Sobre as mudanças percebidas na área próxima à Lagoa das Bateias, 75\% dos entrevistados se referiram à urbanização da área, 17\% resumiram, em uma palavra e em tom de descontentamento, a percepção de mudança: "tudo" (ressalta-se que esses moradores foram relocados, durante o processo de construção do Parque para um loteamento localizado um pouco mais distante), e $8 \%$ destacaram o aumento da frequência de pessoas oriundas de outros bairros da cidade que passaram a usá-la como área de lazer.

Da análise dos dados, percebe-se que os riscos e as vulnerabilidades ambientais são sobrepostos por problemas de ordem diversa, ora econômicos, ora sociais ou infraestruturais, e os ambientais, por sua vez, são ignorados, quando não interpretados como problemas de fácil solução. Sobre o reconhecimento de problemas dentre os moradores das áreas do entorno das Unidades de Conservação, é interessante observar que os problemas ambientais foram praticamente nulos nas respostas, sendo elencados, predominantemente, em ambas as comunidades, problemas econômicos (falta de emprego), problemas sociais (saúde) e problemas de infraestrutura (falta de asfaltamento e iluminação de vias). Como problema ambiental, contraditoriamente, os moradores da proximidade da Lagoa do Jurema elencaram justamente a própria lagoa como um problema para a comunidade, associando a ela a proliferação de doenças e utilização da área como esconderijo de bandidos. Neste sentido, na contramão da conservação ambiental, um dos moradores da vizinhança chegou a afirmar que a melhor solução seria a retirada da lagoa e a implantação de algum tipo de comércio por parte da prefeitura.

A análise temporal revela que a criação do Parque das Bateias, com projeto urbanístico voltado para a frequência da população - carente de espaços públicos de lazer ou para realizar caminhadas e passeios -, acabou impulsionando o processo de urbanização e valorização da região. Assim, 33\% dos moradores deste entorno destacaram este aspecto, associando positivamente a criação do parque com a valorização imobiliária local devido à urbanização da área da Lagoa das Bateias, 
atribuindo, assim, valor positivo à lagoa. No entanto, 17\% afirmaram considerar a área do Parque ainda como descuidada. A metade dos entrevistados, contudo, considerou aquela vizinhança como um bom lugar de se morar.

Nesse sentido, a representatividade das lagoas para as duas comunidades assume sentidos distintos e opostos, o que se relaciona mesmo com o grau de cuidado e de presença do estado em cada uma das áreas.

Assim, por um lado, se a vizinhança da Lagoa das Bateias atribui valor positivo à lagoa, o mesmo não acontece, contudo, com os moradores do entorno da Lagoa do Jurema, mais abandonada e sem nenhuma ação de recuperação ou tratamento urbanístico. Neste grupo, uma grande parte dos entrevistados atribui à própria lagoa o principal problema que enfrentam, vinculando sua existência às infestações de doenças, mosquitos e animais peçonhentos, propiciando esconderijo de bandidos e acúmulo de lixo, além dos frequentes alagamentos das casas nos períodos de chuva.

Para essas comunidades residentes no entorno dos parques, os espaços que habitam são únicos, pois, moldados por elas, revelam os seus laços, as suas identidades, os seus conflitos e os seus desejos, como lugares de moradia e de convivência social. A este respeito, a maioria dos moradores entrevistados as define como lugares de fácil acesso, tranquilos e bons de morar, enquanto menos da metade as considera como áreas esquecidas pelo poder público, com uma gama de problemas de ordens diversas, sobretudo infraestruturais.

O espaço socialmente habitado é produto de uma sociedade que sobre ele atua. A essa sociedade, produtora e produto desse espaço, em que cada habitante da cidade o constrói e dele usufrui, individual e coletivamente, cabe o papel de observá-lo com olhar mais crítico na perspectiva de sempre melhorá-lo, uma vez que suas explicações são subjetivas, podendo estar, e muitas vezes estão camufladas.

\section{Considerações finais}

Os estudos de percepção ambiental, disseminados, sobretudo a partir do ano de 1973 pela UNESCO vêm, ao longo do tempo, se consolidando como sinalizadores para a compreensão da totalidade existente nas relações entre o homem e o ambiente, de forma ampla e integradora, que considera as complexidades envolventes e que, portanto, não se resume à extrema especialização do perceptível.

Pela pesquisa foi perceptível que a noção de Unidade de Conservação e de Parque Municipal existente entre os moradores do entorno das áreas é superficial, 
quando não é nula. Para essas pessoas, que em sua maioria não teve nenhum contato com ações de sensibilização ou de educação ambiental, importa muito mais seu próprio bem-estar e as relações pessoais com o lugar em que moram do que o valor ambiental que este possa ter para a sociedade ou para as condições ambientais da região.

Comprova-se, por outro lado, a necessidade de uma política ambiental na cidade que priorize a participação social das comunidades desde as etapas iniciais de reflexão sobre os projetos ambientais e não apenas nas etapas finais do processo, quando a normatização está pronta e acabada para ser aplicada, impactando a vida de sujeitos excluídos da etapa mais importante, que é o planejamento, a tomada de decisão e a reflexão. Qualquer projeto ambiental, a exemplo da criação de Unidades de Conservação e Parques Municipais, que almeje se consolidar como estratégia para a melhoria da qualidade de vida socioambiental, não pode prescindir da noção de que é resultado da coletividade, ou seja, deve estar associado com o aspecto principal de que emanou de uma decisão da maioria e, para isso, faz-se necessário que a população participe desde a etapa de reflexão. Assim, a gestão pública deve estar consciente de que a construção de uma política ambiental não se restringe à sala de um gabinete administrativo, ela vai além, e tem como princípio que a participação social é o termômetro para a consolidação das decisões tomadas coletivamente.

É nesse sentido que esta pesquisa tenta destacar a importância da Percepção Ambiental como ferramenta de gestão, pois além de se referir a um instrumento de avaliação da política ambiental implementada, transforma-se num feedback para a estratégia educativa mais adequada a ser desenvolvida e/ou mudança da proposta de política ambiental em execução.

\section{Referências}

\section{ALMEIDA, L. Q. De; CARVALHO, P. F. Vulnerabilidades e Riscos}

Socioambientais de Rios Urbanos. Estudo de caso na Bacia Hidrográfica do Rio Maranguapinho, Região Metropolitana de Fortaleza. In: Seminário Nacional sobre o Tratamento de Áreas de Preservação Permanente em Meio Urbano e Restrições Ambientais ao Parcelamento do Solo - APPurbana2007. São Paulo: FAU-USP, 2007.

BAHIA. Lei n 1.410, de 05 de junho de 2007. Código Municipal do Meio Ambiente de Vitória da Conquista. Disponível em: <http://www.pmvc.com.br>. Acesso em: 22 mai. 2009. 
BRASIL. Lei $\mathbf{n}^{\mathbf{0}}$ 9.985, de 18 de julho de 2000. Institui o Sistema Nacional de Unidades de Conservação da Natureza. Disponível em:

<http://www.planalto.gov.br/ccivil/Leis/L9985.htm>. Acesso em: 10 abr. 2009.

CARLOS, Ana Fani Alessandrini. (Re) produção do espaço urbano. São Paulo: Edusp, 1994.

CORRÊA, Roberto Lobato; ROSENDAHL, Zeny, orgs. Cultura, Espaço e o Urbano. Rio de Janeiro: EDUERJ, 2002.

Paisagem, tempo e cultura. 2. ed. Rio de Janeiro: EDUERJ, 2004.

CORRÊA, R. L. Monumentos, política e espaço. Geocrítica / scripta nova. Revista electrónica de geografía y ciencias sociales. Barcelona: Universidade de Barcelona, 15 de fevereiro de 2005, vol. IX, núm. 183. Disponível em <http://www.ub.es/geocrit/ sn/sn-183.htm>. Acesso em: 15 abr. 2013.

FERNANDES, Roosevelt S.; FERNANDES, Sabrina T.; DE SOUZA, Valdir José; PELISSARI Vinicius Braga. Uso da Percepção Ambiental com Instrumento de Gestão em Aplicações Ligadas às Áreas Educacional, Social e Ambiental, 2003. Disponível em <http://www.redeceas.esalq.usp.br/noticias/Percepcao_Ambiental.pdf>. Acesso: 14/08/10.

FERRAZ, Ana Emilia de Quadros. O Urbano em construção: Vitória da Conquista: um retrato de duas décadas. Edições UESB, 2001.

GIL, Antônio Carlos. Métodos e técnicas de pesquisa social. 6. ed. São Paulo: Atlas, 2011.

GOMES, P. C. C. A condição urbana. Ensaios de geopolítica da cidade. Rio de Janeiro: Bertrand Brasil, 2002.

IBGE (Instituto Brasileiro de Geografia e Estatística). Censos demográficos.

Disponível em: <www.ibge.gov.br>. Acessos em: 02 abr. 2009; 12 mai. 2013.

LYNCH, Kevin. A imagem da cidade. Tradução Jefferson Luiz Camargo. São Paulo: Martins Fontes, 1997.

MORIN, Edgard. A cabeça bem-feita: repensar a reforma, reformar o pensamento. $9^{\text {a }}$ Ed. Rio de Janeiro: Bertrand Brasil, 2004.

OLIVEIRA, Marília Flores Seixas de; OLIVEIRA, Orlando J. R. de. (Orgs.) De Olho na mata: fotografia, educação ambiental e sustentabilidade. Vitória da Conquista: UESB, Petrobrás, 2003.

PMVC. Relatório do Censo IBGE 2000. Vitória da Conquista: Núcleo de Projetos da Prefeitura Municipal de Vitória da Conquista, 2000. Disponível em:

<http://www.pmvc.com.br>. Acessos em: 22 mai. 2009.

PMVC. Decreto no 8.594, 1996. Vitória da Conquista: Tombamento de áreas de nascente, 1996. Disponível em: 〈http://www.pmvc.com.br〉. Acessos em: 22 mai. 2009. 
SANTOS, Milton. Configuração Territorial e Espaço. In: Metamorfoses do Espaço Habitado. São Paulo: Edusp, 1988.

A Urbanização desigual: a especificidade do fenômeno urbano em países subdesenvolvidos. 2. ed. Vozes, 1982.

TUAN, Yi-Fu. Topofilia: um estudo da percepção, atitudes e valores do meio ambiente. São Paulo: Difel, 1980.

Recebido em: 18/11/2017

Aceito para publicação em: 10/12/2017 